\title{
BMJ Open Feasibility of a web-based suicide awareness programme for Asian American college students
}

\author{
Heeseung Choi, ${ }^{1}$ Hanjong Park, ${ }^{2}$ Marie L Suarez, ${ }^{3}$ Chang Park, ${ }^{3}$ \\ Zhongsheng Zhao, ${ }^{3}$ Diana J Wilkie ${ }^{3,4}$
}

To cite: Choi $\mathrm{H}$, Park $\mathrm{H}$, Suarez ML, et al. Feasibility of a web-based suicide awareness programme for Asian American college students. BMJ Open 2016;6: e013466. doi:10.1136/ bmjopen-2016-013466

- Prepublication history for this paper is available online. To view these files please visit the journal online (http://dx.doi.org/10.1136/ bmjopen-2016-013466).

Received 14 July 2016 Accepted 28 November 2016

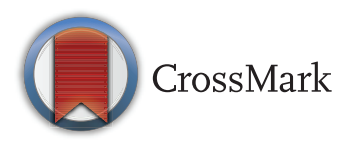

${ }^{1}$ College of Nursing and the Research Institute of Nursing Science, Seoul National University, Seoul, Republic of Korea

${ }^{2}$ College of Nursing Science, Kyung Hee University, Seoul, Republic of Korea

${ }^{3}$ College of Nursing, University of Illinois at Chicago, Chicago, Illinois, USA

${ }^{4}$ Department of Biobehavioral Nursing Science, Center of Excellence in Palliative Care Research, College of Nursing, University of Florida, Gainesville, Florida, USA

Correspondence to Dr Hanjong Park; hparkchicago@gmail.com

\section{ABSTRACT}

Objective: The Truth about Suicide video has been widely used but has never been empirically tested regarding its cultural appropriateness for Asian

Americans. The purpose of the study was to determine the feasibility of using the video in a web-based suicide awareness programme for Asian American and non-Hispanic white college students.

Methods: A cross-sectional, comparative, web-based study was conducted with 227 Asian Americans and 204 non-Hispanic whites at a university in the Midwest region of the USA. Study participants completed a questionnaire measuring their cultural orientation and attitudes towards suicide, watched the 27 min video, completed a debriefing session and evaluated the video's overall suitability.

Results: Asian Americans rated the suicide awareness video significantly lower for cultural relevance than did non-Hispanic whites ( $F=5.479, p=0.02)$. Collectivist cultural orientation was a significant predictor for cultural relevance, credibility and appeal; however, evaluation of the video's cultural relevance was negatively affected by Asian ethnicity.

Conclusions: Cultural orientation and race/ethnicity should be strongly considered when web-based suicide awareness programmes are developed for college students.

\section{INTRODUCTION}

Suicide has been the second leading cause of death for young adults in the USA. ${ }^{1}$ The prevalence of suicidal behaviours was highest among young adults aged 18-29 years, typical ages of college students. The National College Health Assessment II $^{2}$ showed that $6.4 \%$ of college students seriously considered suicide and $1.1 \%$ attempted suicide within the previous 12 months. Suicide is also the second leading cause of death for Asian Americans aged 15-24 years. ${ }^{3}{ }^{4}$ Asian American college students have exhibited higher rates of suicidal ideation and suicide attempts compared with white students. ${ }^{5} 6$ Regardless of the high risk for suicide, Asian

\section{Strengths and limitations of this study}

- Although the cross-sectional design limits our conclusions to the students who participated in this study and cannot be generalised to all Asian American students, the study allowed us to take an important step in understanding whether this particular video could be useful for disseminating a suicide awareness message via the internet for Asian American and non-Hispanic white (NHW) college students.

- Our study showed that The Truth about Suicide is credible and appealing for Asian American and NHW college students, although the content needs to be modified to reflect the cultural values of Asian American students.

- Whereas there is a potential sampling bias inherent in limiting the sample to students who have access to computers, students use computers frequently, and computers are freely available on the university campus.

- More diverse ethnic groups of students need to be included in future studies.

- In terms of the use of web-based suicide prevention programmes, examining the extent to which the programmes have impacted help-seeking behaviours of the audience is another important area for future studies.

American college students are less likely to seek mental healthcare than non-Hispanic white (NHW) college students, ${ }^{7}$ even after controlling for prevalence of mental disorders. $^{8}$

To address this serious public health problem, various suicide prevention strategies, including screening, education and means restriction, have been implemented for college students. Well-known and commonly used programmes are Campus Connect, Student Support Network and At-risk for University and College Faculty. ${ }^{9}$

One of the most widely used suicide prevention videos is The Truth about Suicide: Real Stories of Depression in College (The Truth about Suicide), developed by the American 
Foundation for Suicide Prevention (AFSP). ${ }^{10}$ The Truth about Suicide depicts key features of depression and facts, statistics, and signs of suicidal behaviours among college students to raise suicide awareness and emphasise the importance of early identification of depression and suicide risks. The video particularly focuses on interviews with people who have lost a loved one to suicide and the testimonies of students who have experienced depression and suicidal ideation. The Truth about Suicide has been widely used by various colleges and communities in the USA, but it has never been empirically tested in terms of its cultural appropriateness for Asian Americans, a group of special concern for suicide. ${ }^{34} \mathrm{In}$ addition, the video has been used only in face-to-face group settings and has not been delivered through the internet, an approach that may be useful for suicide awareness and prevention among college students. ${ }^{11}$

Disseminating suicide prevention programmes using videos and web-based technology is likely to increase the accessibility and appeal of the information to college students ${ }^{11}$ because this approach is not bound to identified barriers that face-to-face programmes have, including lack of time and resources and inflexibility of the content. ${ }^{12}$ Among 18 studies examining the effectiveness of online mental health interventions in facilitating help-seeking among people aged 14-25 years, 15 have shown evidence of the positive effects of online interventions. ${ }^{13}$ Facilitators to help-seeking include accessibility to online resources, anonymity, trust, confidentiality, low levels of stigma, perceived benefits and increases in mental health knowledge. ${ }^{13} 14$ These facilitators are particularly important for Asian Americans who are reluctant to seek professional help for mental health problems due to stigma and underestimation of consequences of mental health problems. ${ }^{8} 15$ In addition, videos that deliver emotionally charged messages are shown to be effective in improving attention and enhanced recall of presented messages, and thus the suicide prevention programme using videos was found to be a safe and effective education strategy in this study. ${ }^{16}$

When widely disseminating web-based suicide prevention programmes for college students, it is important to ensure that the content and delivery method fit with their cultural orientation and attitudes towards suicide among the target population. Cultural orientation refers to 'the degree to which individuals are influenced by and actively engage in the traditions, norms and practices of a specific culture, ${ }^{17}$ and it influences the way individuals process information and subsequent attitude formation'. ${ }^{18}$ Depending on the degree to which people in a society are integrated into groups, cultural orientation can be categorised as either individualism (IND) or collectivism (COL). ${ }^{19}$

Asian cultures are often regarded as collectivistic, whereas the American culture is considered individualistic. ${ }^{20}$ People who are mainly influenced by collectivistic orientations tend to value family 'honor and loyalty' and social norms and thus may focus on the social and relationship context when exploring issues associated with suicide. People with individualistic orientations tend to exhibit more permissive attitudes towards suicide than the collectivists. ${ }^{21}$ Thus, these differences in cultural orientation and attitudes towards suicide are important to consider when innovating suicide awareness programmes for college students. However, it is still not clear how cultural orientations and attitudes towards suicide will affect the degree to which students will find the video acceptable and suitable for them. So far, there has been little research on web-based dissemination of suicide awareness messages for college students, particularly Asian Americans, except one pilot study of a webbased intervention for college students that included Asian students in the sample $(\mathrm{n}=21){ }^{22}$

It is critical to conduct a feasibility study when launching a new intervention. The main issues to consider when assessing the feasibility of a new intervention are implementation, acceptability and demand. ${ }^{23}$ Implementation refers to the extent to which a newly developed programme can be successfully delivered to the target audience and focuses on degrees of success and failure of execution and the amount and types of resources required for implementing the programme. ${ }^{23}$ Acceptability includes satisfaction and perceived appropriateness and addresses how the target audience reacts to the intervention. Demand is determined by assessing the fit between the programme and the target audience, perceived demand, and expressed interests or intention to use. ${ }^{23}$

For implementation, we assessed recruitment and retention, patterns of missing data, amount of time required for execution and degree of responses in the debriefing session. For acceptability and demand, we assessed the suitability rating (ie, cultural relevance, credibility, appeal) and participants' responses to the open-ended questions of the debriefing session.

Owing to the known strengths and benefits, the webbased suicide prevention programmes have been widely used for various groups of people. ${ }^{22}{ }^{24-26}$ However, so far, studies systematically examining the feasibility associated with web-based dissemination of suicide awareness messages for college students have not been conducted yet. The specific aims of this study were to (1) determine the feasibility (ie, implementation, acceptability, demand) of a web-based suicide awareness study that included an online debriefing session among Asian American and NHW college students; (2) compare the students' suitability ratings for a web-based suicide awareness video; and (3) determine the effects of cultural orientation and attitudes towards suicide on the suitability ratings of the two ethnic/racial groups. NHWs were selected as the reference group because this majority group comprised $72.4 \%$ of the total US population in 2013 and because the prevalence of suicidal behaviours among NHWs aged 15-24 years was similar to that of the total population. ${ }^{27}$ Additionally, NHWs were expected 
to differ from Asian Americans with respect to cultural orientation. $^{20}$

\section{METHODS}

\section{Study design}

This cross-sectional, comparative study was conducted at one university in the Midwest region of the USA during the spring of 2011. The AFSP gave approval for digitising and using the video, The Truth about Suicide, to achieve the study aims.

\section{Sample and setting}

More than 24000 students attend the university, and Asian Americans represent almost 21\% of the student body. Study inclusion criteria were: (1) ethnic/racial heritage was Asian or NHW; (2) English-speaking; (3) aged 17 years or older; and (4) access to a Windows-based computer with components for playing audio and video files (eg, Windows Media Player). The calculated desired sample size was 168 for each of the two ethnic groups (336 participants in total) for the aims of this study required to perform analysis of covariance (ANCOVA) and multiple linear regressions with a power of 0.80 , expected small-to-medium effect sizes, and a significance level of $0.05 .^{29}$

In a separate article, we described how we carefully determined which study participants met the inclusion criteria for the main analysis for the study aims. The article focuses solely on the methodology issues and potential bias to be considered when implementing webbased research. $^{29}$

\section{Procedures}

To recruit prospective participants, we posted an announcement on student organisation lists, and on the university announcements page. The brief message described the study purpose, duration of study, compensation and website URL where students were invited to enrol. In addition, instructors announced the study during class after department heads or the directors of the academic programmes gave approval.

Responding students were asked to log into the password-protected secure project website and complete four screening questions for study eligibility. Students were excluded if they self-reported that they (1) were currently depressed; (2) were currently having thoughts of ending life; (3) lost someone to suicide in the past 6 months or (4) had previously seen The Truth about Suicide video. In addition, students who were physically unable to complete a computerised questionnaire were excluded from the study. Students who answered yes to any of the screening questions were excluded, but were encouraged to seek mental health services and directed to the university student counselling centre information page. For this feasibility study, students who were currently affected by depression or suicide were excluded for safety reasons because the effects of the web-based delivery of the video on students currently depressed, suicidal or recently affected by suicide have not been examined.

Eligible students were asked to create a unique encrypted identification number and password and then were directed to the information letter page that was equivalent to an online informed consent. Only students who clicked the 'Yes, I agree to participate in this study' option on this webpage were transferred to the survey page and asked to complete the baseline survey before watching the video. After submitting the baseline survey, students accessed the page that hosted the link to the streaming video. The video was linked to a private and unlisted YouTube site. We asked students to watch the video for the entire duration of $27 \mathrm{~min}$ and then to complete a debriefing session and a questionnaire related to their impressions and evaluation of the video.

The web-based debriefing session was developed in consultation with experts in suicide prevention, including the Asian American Suicide Prevention Initiative. The debriefing session, which is an essential component for the suicide prevention programmes, was thoughtfully designed to provide a safe and confidential setting to allow participants to share thoughts, feelings and experiences related to depression, suicide and The Truth about Suicide. The topics and types of questions used for the web-based debriefing session were similar to those used for the face-to-face debriefing sessions conducted in a group setting. Sample questions include 'What are your feelings and/or reactions after viewing the video?' 'What about the video impacted you the most?' and 'Were there any questions about suicide you were confused about that were answered in the video?' Participants were asked to type their responses to these essay-type questions.

We allowed students an opportunity to view the video and complete the standardised questionnaire at their own pace and on their own computer. Therefore, students could log-off the website and return to continue from their exit point (eg, complete the questionnaire items or view the video) at a later time by retaining their access code. We expected that this aspect of confidentiality and self-pacing would encourage an honest opinion from each student since people may feel comfortable to report their concerns or problems honestly when they assured their privacy through confidentiality or anonymity as reported in previous studies. ${ }^{30} 31$ On successful completion of the assessments, we offered participants a $\$ 20.00$ gift card; the data set for receiving it was not linked to other study data.

The study website was hosted on the College of Nursing secure server, and website access was restricted to registered study participants. The website programming recorded time on each webpage. The study questionnaire was programmed for user friendliness and pilot tested with 10 volunteer students to assure acceptable usability for the target audience (figure 1). 

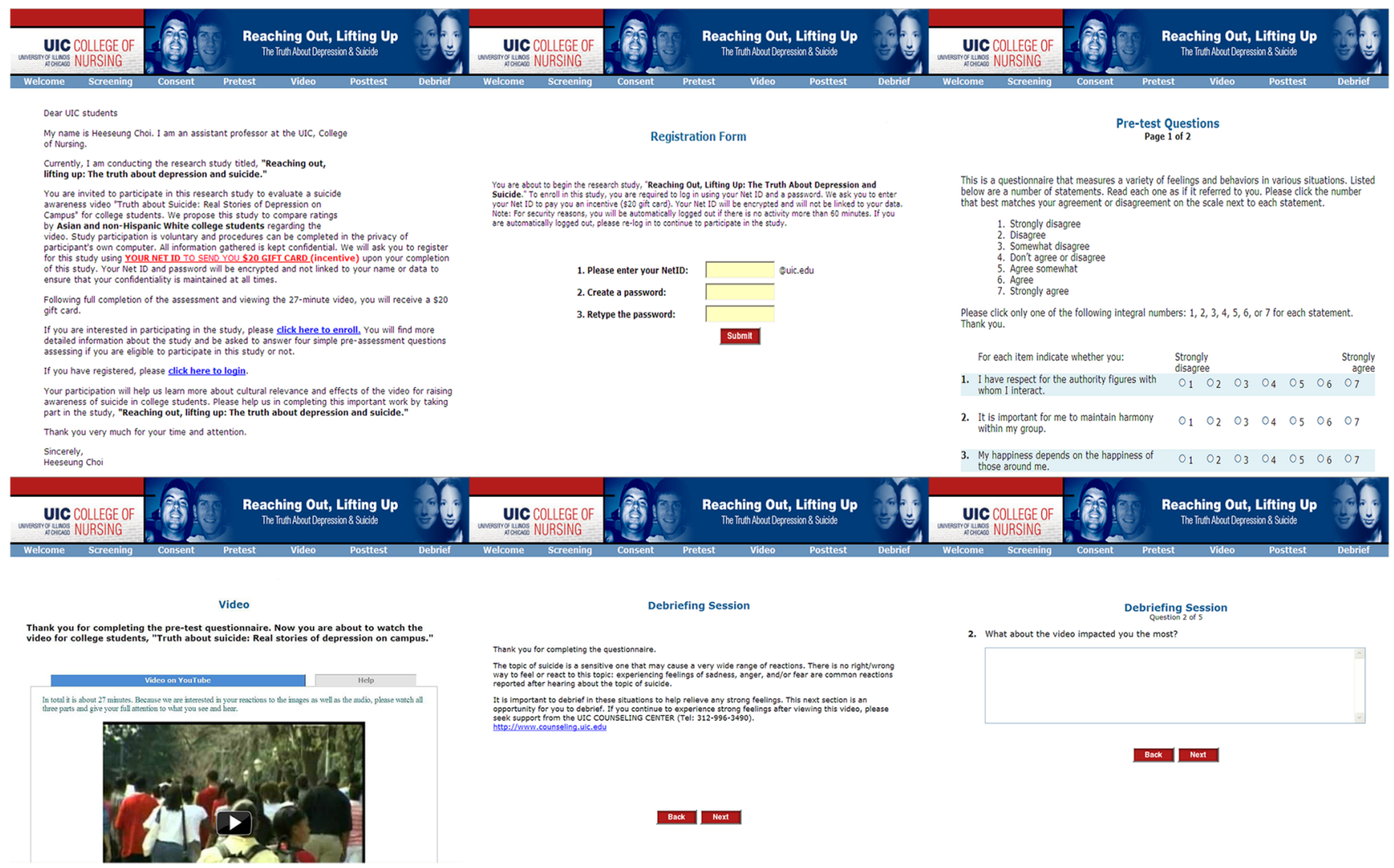

Bact now

Figure 1 Screenshot examples of Suicide Awareness Study website.

\section{Measures}

Attitudes towards suicide

We used a short version (10-item) of the Suicide Opinion Questionnaire (SOQ), which originally consisted of 100 self-report items assessing diverse domains of beliefs and perceived factual knowledge about suicide. ${ }^{32}$ Different versions of the SOQ have been used for a variety of samples, including college students. ${ }^{33}$ In a study of undergraduate college students, Limbacher and Domino ${ }^{34}$ reported that the SOQ discriminated among students who had attempted suicide, contemplated suicide or had not attempted suicide.

Among the original items, we used 10 items assessing one's attitudes towards suicide. Examples include 'I would feel ashamed if a member of my family committed suicide', and 'People do not have the right to take their own lives'. Each item is rated on a Likert scale ranging from 1=strongly agree to 5=strongly disagree. Higher scores reflect a more favourable attitude towards suicide. This scale showed acceptable reliability for our sample $(\alpha=0.71)$.

\section{Cultural orientation}

We used IND-COL, a 24-item scale to measure the cultural orientation towards IND and COL. ${ }^{19}$ The 12-item IND subscale emphasises a view of the self as autonomous and distinct from others, emphasising both equality (eg, I often do my own thing) and inequality (eg, Competition is the law of nature). The 12-item COL subscale stresses a self that is part of a group or belonging to a collective, with acceptance of hierarchy (eg, I respect the majority's wishes in groups of which I am a member) and equality (eg, 'I feel good when I cooperate with others). This scale was developed based on the orthogonal model of IND-COL rather than the unidimensional bipolar model. ${ }^{35}$ All items are answered on a seven-point scale ranging from $1=$ strongly disagree to $7=$ strongly agree. The subscale score is calculated by summing all the items of the subscale, and each subscale score is calculated independently. All items have been shown to form internally consistent scales $(\alpha=0.67-0.74)$ with past samples of adolescent and adult populations ${ }^{19}$ and with our sample (IND: $\alpha=0.79$, COL: $\alpha=0.81$ ).

\section{Suitability}

We adapted the Video Evaluation Questionnaire ${ }^{36}$ to make it relevant to The Truth about Suicide video delivered via the internet. The original questionnaire was used to evaluate the cultural sensitivity and credibility of an AIDS education video, which addressed another sensitive issue. The reliability of the original subscale ranged from 0.78 to $0.92 .^{36}$ As modified for our study, the suitability scale is a Likert-type scale and consists of three subscales: cultural relevance ( 5 items), credibility (10 items) and appeal (9 items). The cultural relevance subscale measures the consistency of the video with values, habits, experience and needs of the viewers. Examples include 'How much did you feel the video 
reflected your social reality and contexts?' and 'How well did the video represent behaviours from your peer group, family or community?'. The credibility subscale measures the expertise of presenters and trustworthiness of the video content. An example includes 'How much did you feel the video gave all the correct information about suicide?'. Finally, the appeal subscale measures the overall quality (audio/visual) and completeness of the video. Examples include 'How much did you like the speed and style in which the presenters spoke?' and 'How "professional" did you feel the video was?'. Response categories range from $1=n o t$ at all to $7=$ very much. Higher scores reflect a higher suitability of the video. All subscales showed good reliability for our sample (cultural relevance: $\alpha=0.80$, credibility: $\alpha=0.95$, appeal: $\alpha=0.89)$. Using this standardised tool, we assessed whether participants perceived that the video was culturally relevant, credible and appealing to them.

\section{Sociodemographic information}

In addition to the main study variables, demographic information was gathered to describe the sample. These variables included age, education level, gender, race and ethnicity.

\section{Manipulation check}

To determine the student's recall of the video content and hence their engagement with the video, we developed a manipulation check tool. It consisted of five true/false questions, which assessed participants' postvideo knowledge level. Scores could range from 0 to 5 , with a higher score indicating better comprehension of the video.

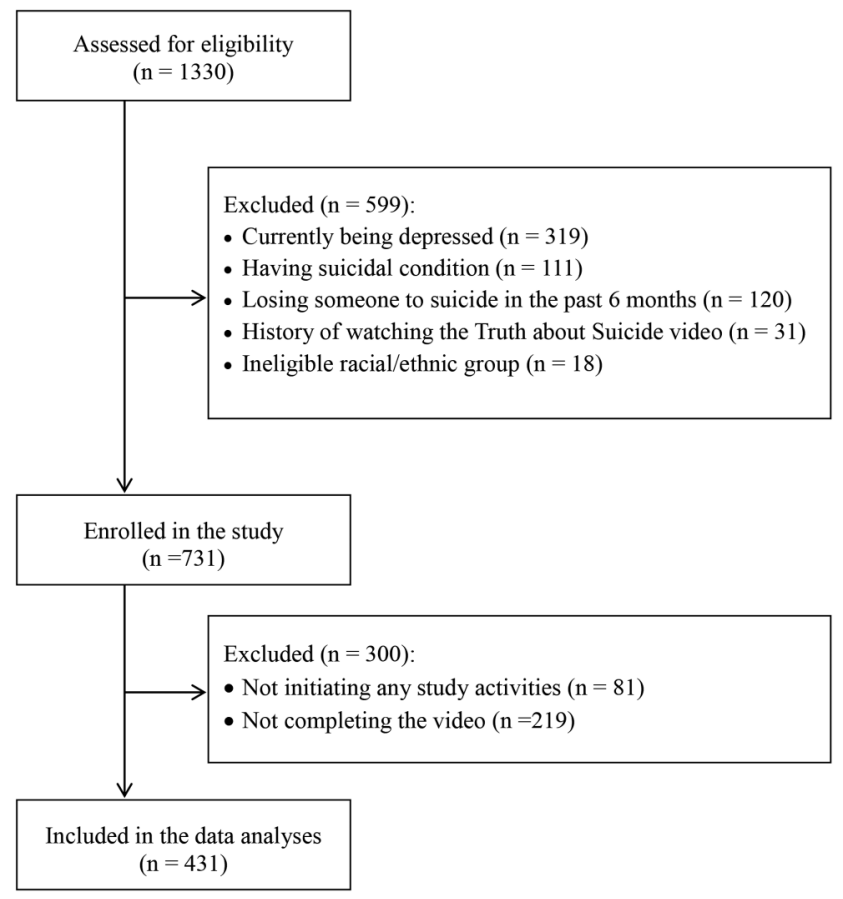

Figure 2 Flow chart of study participants $(\mathrm{N}=431)$.
Among those measures, the participants completed the attitudes towards suicide, cultural orientation and sociodemographic questionnaires before watching the video (baseline survey). Also, they completed the suitability scale, manipulation check items and the debriefing session after watching the entire video (post-test).

\section{Data analyses}

The study website was linked to a Structured Query Language (SQL) Server 2000 database hosted by the university for automatic data collection, and only secure connection was allowed. The unique identifiers were encrypted, and there was no decryptor available. Therefore, the data were coded but anonymous. Data were exported to an Excel file to facilitate data analysis in SPSS V.22.0 and STATA V.13.0. Group differences on demographic characteristics were examined using the $\chi^{2}$ test and t-test. For specific aims 2 and 3, we performed ANCOVA and multiple linear regressions. In addition to demographic variables, we used the manipulation check tool scores to differentiate groups of participants who appeared to watch or not watch the video.

A content analysis method was used to analyse the text data collected through the debriefing session. The aim of the content analysis is to describe a phenomenon, such as emotional reactions of the respondents to a certain situation. Research team members read the text data repeatedly to acquire a general understanding of the data and then independently coded the data. We then assessed the congruity of the coding and discussed and resolved discrepancies in the coding. Next, we identified an initial coding scheme, categories and main themes in the data and analysed the frequencies of similar responses. Only the findings relevant to the feasibility of the web-based suicide awareness programme are reported in the present paper.

\section{RESULTS}

\section{Feasibility of the web-based suicide awareness video} programme

To evaluate the feasibility of the application of the suicide video, we checked the recruitment and retention of study participants, patterns of missing data and amount of time required to complete study elements. Also, we explored study participants' shared feelings and thoughts regarding the video using their responses in the debriefing session.

\section{Recruitment and retention}

We were able to successfully complete data collection in 10 weeks. A total of 1330 students were screened for study participation, but 599 did not meet the eligibility criteria. Among the 599 ineligible students, 319 were currently depressed, 111 were suicidal, 120 had lost someone to suicide in the past 6 months (most likely because of an off-campus suicide of students, of which the counselling centre staff informed the study team 
Table 1 Demographic characteristics of study sample $(\mathrm{N}=431)$

\begin{tabular}{|c|c|c|c|c|c|c|}
\hline \multirow[b]{2}{*}{ Variable } & \multicolumn{2}{|c|}{ NHW $(n=204)$} & \multicolumn{2}{|c|}{ Asian $(n=227)$} & \multirow[b]{2}{*}{$\chi^{2}$ or $t$} & \multirow[b]{2}{*}{ p Value } \\
\hline & $n(\%)$ & Mean (SD) & Mean (SD) & Mean (SD) & & \\
\hline \multicolumn{7}{|l|}{ Gender } \\
\hline Male & $44(21.6)$ & & $70(30.8)$ & & 4.744 & 0.029 \\
\hline Female & $160(78.4)$ & & 157 (69.2) & & & \\
\hline \multicolumn{7}{|l|}{ Education } \\
\hline Undergraduate & $126(62.7)$ & & $159(70.7)$ & & 3.053 & 0.081 \\
\hline Graduate & 75 (37.3) & & 66 (29.3) & & & \\
\hline \multicolumn{7}{|l|}{ Age } \\
\hline $17-19$ & $24(11.8)$ & & $70(30.8)$ & & 28.535 & $<0.0001$ \\
\hline 20-29 & $151(74.0)$ & & 145 (63.9) & & & \\
\hline \multirow[t]{2}{*}{30 and older } & 29 (14.2) & & $12(5.3)$ & & & \\
\hline & & $24.6(6.69)$ & & $22.17(4.05)$ & -4.505 & $<0.0001$ \\
\hline
\end{tabular}

when these high numbers were reported to the centre), 31 had seen The Truth about Suicide previously and 18 were from other racial/ethnic groups. A total of 731 students registered in the study: 349 Asian Americans and 301 NHWs. Among the 731 students, 81 did not initiate any study activities other than registration. In addition, early data monitoring revealed that 219 students (122 Asian American and 97 NHW students) who had completed the study at that point did not watch most or all of the video. To ensure that participants watched the entire video and completed all parts of the study, we introduced software controls to prevent participants spending an insufficient amount of time on the critical study activity-the video. Detailed information and issues related to data monitoring and valid engagement with the video are discussed in a separate article. ${ }^{29}$

Finally, a total of 431 students (227 Asian Americans and 204 NHWs) who watched the entire video and completed the questionnaires were included in the final analysis for this study (excluding the 81 students who did not initiate any study activities and the 219 students who did not watch at least $26 \mathrm{~min}$ of the video; figure 2). Among the 431 participants, about $26.5 \%$ were male, and $66 \%$ were undergraduate students. Compared with NHW students, the Asian American students were younger $(\mathrm{p}<0.0001)$ and more often male $(\mathrm{p}=0.029$; table 1). The mean scores on the manipulation check tool were $4.19(\mathrm{SD}=0.83)$ and $3.93(\mathrm{SD}=0.91)$ for the NHW and Asian American students, respectively.

\section{Missing data}

Both Asian American and NHW students rarely skipped questionnaire items; $<2 \%$ of values were missing. Patterns of missing data were completely at random for both NHW (Little's MCAR test: $\chi^{2}=1408.177$, df $=1325$, $\mathrm{p}=0.055$ ) and Asian American students (Little's MCAR test: $\left.\chi^{2}=1892.330, \mathrm{df}=1957, \mathrm{p}=0.850\right)$.

\section{Amount of time required to complete study elements}

The amount of time required to complete study elements, including pretest, post-test and video, was not significantly different between NHW and Asian American students. The median time spent to complete the pretest was $8.1 \mathrm{~min}$ for NHW students and $8.2 \mathrm{~min}$ for Asian American students $(\mathrm{z}=-0.883, \mathrm{p}=0.377)$. For the post-test, NHW students spent $9.1 \mathrm{~min}$, and Asian American students spent $9.7 \mathrm{~min}$ to complete the questionnaire items $(\mathrm{z}=-1.523, \mathrm{p}=0.128)$. The median time spent viewing the video was 29.6 min for NHW students and $31.0 \mathrm{~min}$ for Asian American students $(\mathrm{z}=-0.604$, $\mathrm{p}=0.546)$.

\section{Debriefing session}

An important finding of this study is the feasibility of conducting a web-based debriefing session for college students. Nearly all of the participants gave rich responses to the debriefing questions. Only 14 participants answered only the yes/no and multiple choice questions and did not answer any of the essay-type questions. The other students answered the fixed response items and also shared their thoughts and feelings related to depression and suicide and their feedback on The Truth about Suicide.

Common feelings and/or reactions that participants reported experiencing after viewing the video included sadness, surprise and shock, empathy, sympathy and being overwhelmed with many feelings. Almost $40 \%$ of participants indicated that they were most impacted by the real, personal stories of the family and friends of suicide victims or by the suicide survivors, particularly the impact of suicide on the lives of the people left behind. One participant stated that "the testimonials really made it apparent how suicide doesn't just affect the victim".

Many participants $(n=185)$ also reported that they were impacted by the facts about depression and suicide presented in the video, especially the high prevalence of depression and suicide. They expressed a higher awareness of the need to watch for signs of depression to be able to help friends and the need to take immediate action, take depression seriously and talk openly about suicide. One participant said: 
When the presenters said that depression is a medical illness, it totally changed my view of seeing depression. Before viewing this video, I thought depression is just a sign of weakness in personality. But I realize that it is an illness which can be treated professionally.

\section{Ethnic differences in suitability ratings}

ANCOVA results indicated that Asian American college students rated the video significantly lower on cultural relevance than NHW students after controlling for demographic characteristics, cultural orientations, attitudes towards suicide and manipulation check $(\mathrm{F}=5.479$, $\mathrm{p}=0.02$; table 2). Overall, Asian American students rated the video lower on credibility and appeal than NHW students, but the group differences were not statistically significant.

Participants' responses to the debriefing questions also confirmed that the cultural relevance of the video needs to be improved for Asian American students. A student mentioned:

Being Asian, I would have liked to see more of a focus on Asians in the video, and the causes of suicide in the Asian community, which is very different from in other communities. Particularly the role of academics, the 'model minority' myth, and social/familial pressures, as I have known a couple of Asians who have committed suicide precisely due to these issues...

Another student also said that "there was so little representation of minority groups in the video" and "no Hispanic or Asians were giving testimonials." An NHW student mentioned that "I think it would be interesting to see the effects of depression in different cultural backgrounds. Other than one African American male, the video mainly focused on Caucasians."

\section{Effects of attitudes towards suicide and cultural} orientation on the suitability ratings

The attitudes towards suicide mean scores were 3.57 $(\mathrm{SD}=0.66)$ and $3.28(\mathrm{SD}=0.64)$ for the NHW and Asian American students, respectively. The individualist cultural orientation mean scores were $5.04(\mathrm{SD}=0.83)$ and $4.89(\mathrm{SD}=0.83)$ for the NHW and Asian American students, respectively. In contrast, the collectivist cultural orientation mean scores were $4.80(\mathrm{SD}=0.76)$ and 5.23 $(\mathrm{SD}=0.75)$ for the NHW and Asian American students, respectively.

Multiple linear regressions were used to examine relationships between the predictors (cultural orientation, manipulation check scores, age, ethnicity, education level and attitudes towards suicide) and video suitability ratings (ie, cultural relevance, video credibility and video appeal). The contributions of gender, cultural orientation and manipulation check scores were significant for all three ratings. Collectivist cultural orientation $(\beta=0.17-0.18)$ and manipulation check $(\beta=0.17-0.19)$ were the strongest significant predictors for cultural relevance and video credibility. Age $(\beta=0.24)$ and collectivist cultural orientation $(\beta=0.21)$ were the strongest significant predictors for video appeal. Among the video suitability scales, only cultural relevance was negatively affected by Asian ethnicity $(\beta=-0.13, \mathrm{p}=0.020)$, and only video appeal was positively influenced by undergraduate status $(\beta=0.12, p=0.035)$. The contribution of attitudes towards suicide was not significant for any of the suitability ratings (table 3 ).

\section{DISCUSSION}

We report three important findings. First, it is feasible to reach, recruit and retain both Asian American and NHW college students for a web-based suicide awareness study that is reasonable for time involvement and innovative for an online debriefing session. Second, Asian American college students rate The Truth about Suicide video significantly lower on cultural relevance than NHW students after controlling for age, gender, education level, cultural orientation, attitudes towards suicide and manipulation check scores. Third, a collectivist cultural orientation is a significant predictor for cultural relevance, credibility and appeal, but only cultural relevance was negatively affected by Asian ethnicity. These findings are important for guiding future intervention research to prevent suicide among college students, particularly Asian American college students, whose suicide risk is increasing at an alarming rate. ${ }^{20} 37$

\begin{tabular}{|c|c|c|c|c|c|c|c|}
\hline Suitability variable* $^{\star}$ & Ethnicity & Mean $†$ & SD† & Adjusted mean $¥$ & Adjusted SE $\ddagger$ & $F \neq$ & p Value \\
\hline \multirow[t]{2}{*}{ Cultural relevance } & $0 \mathrm{NHW}$ & 5.15 & 1.09 & 5.11 & 0.08 & 5.479 & 0.020 \\
\hline & 1 Asian & 4.82 & 1.02 & 4.86 & 0.07 & & \\
\hline \multirow[t]{2}{*}{ Video credibility } & $0 \mathrm{NHW}$ & 5.77 & 0.93 & 5.74 & 0.07 & 0.815 & 0.367 \\
\hline & 1 Asian & 5.63 & 0.90 & 5.66 & 0.06 & & \\
\hline \multirow[t]{2}{*}{ Video appeal } & $0 \mathrm{NHW}$ & 5.34 & 0.92 & 5.29 & 0.07 & 0.364 & 0.547 \\
\hline & 1 Asian & 5.20 & 0.98 & 5.24 & 0.06 & & \\
\hline
\end{tabular}

${ }^{*}$ Possible value ranged from 1 to 7 .

† Unadjusted.

$\ddagger$ Adjusted for age, gender, education, individualist cultural orientation, collectivist cultural orientation, attitudes towards suicide and manipulation check.

NHW, non-Hispanic whites. 
Table 3 Effects of cultural orientation and attitudes towards suicide on cultural relevance $(N=431)$

\begin{tabular}{|c|c|c|c|c|c|c|}
\hline Variable & $\boldsymbol{\beta}$ & SE & $95 \% \mathrm{Cl}$ & $\boldsymbol{\beta}$ & p Value & $\Delta R^{2}$ \\
\hline \multicolumn{7}{|l|}{ Step 1} \\
\hline Age & 0.02 & 0.01 & -0.01 to 0.04 & $0.09^{*}$ & 0.121 & \multirow[t]{5}{*}{0.045} \\
\hline Gender $($ male $=1)$ & -0.31 & 0.12 & -0.54 to -0.08 & $-0.13^{\star}$ & 0.009 & \\
\hline Education & 0.22 & 0.13 & -0.04 to 0.48 & 0.10 & 0.096 & \\
\hline (undergraduate=1) & & & & & & \\
\hline Ethnicity (Asian=1) & -0.27 & 0.11 & -0.54 to -0.06 & $-0.13^{\star *}$ & 0.011 & \\
\hline \multicolumn{7}{|l|}{ Step 2} \\
\hline Collectivism & 0.23 & 0.07 & 0.10 to 0.36 & $0.17^{\star \star}$ & 0.001 & \multirow[t]{2}{*}{0.079} \\
\hline Individualism & 0.13 & 0.06 & 0.01 to 0.25 & $0.10^{*}$ & 0.037 & \\
\hline \multicolumn{7}{|l|}{ Step 3} \\
\hline Attitudes towards suicide & 0.08 & 0.08 & -0.07 to 0.24 & 0.05 & 0.292 & 0.082 \\
\hline \multicolumn{7}{|l|}{ Step 4} \\
\hline Manipulation check & 0.21 & 0.06 & 0.10 to 0.32 & $0.17^{\star \star}$ & $<0.001$ & 0.110 \\
\hline
\end{tabular}

Our study showed that it is feasible to deliver webbased suicide awareness messages to NHW and Asian American college students. Within a 10-week period, a large number of college students responded to the study recruitment message, and a total of 431 participants successfully completed the study. About 4 of 10 students who logged on to our study website admitted to being affected by depression or suicide. It is possible that students who had been affected by these problems were more likely to respond to the study announcement. The prevalence is similar to that of a recent study with an ethnically diverse college student sample; about $49 \%$ of students were experiencing depressive symptoms $(\mathrm{CES}-\mathrm{D} \geq 16){ }^{38}$ Investigators reported that more than half of their sample (15010 undergraduate and 11441 graduate students) had suicidal ideation, with $2 \%$ of each group reporting it on a regular basis. ${ }^{39}$ About $37 \%$ of undergraduates and $28 \%$ of graduate students who had considered suicide in the past 12 months actually had made preparation for suicide, and $14 \%$ of undergraduates and $8 \%$ of graduate students with serious suicidal ideation had attempted suicide at least once. ${ }^{39}$

The high rates of mental health problems reported by our study participants raised an important issue for researchers and clinicians to consider as they provide web-based suicide prevention programmes. Since the personal ID and password were encrypted and not linked to the participant's name or other personal data, we were not able to identify or track the participants who reported problems. We discussed this issue with the university counselling centre and added to the study website an additional link and information about the counselling service centre. Guaranteed anonymity in a web-based study can elicit high response rates and engagement of participants, ${ }^{40}$ but it prevents researchers from providing further assessment and care for high-risk individuals. This issue is particularly important when delivering messages that might be disturbing to some of the participants. Thus, it is important to assess the safety and acceptability of the message when designing a web-based suicide awareness programme. ${ }^{26}$ Issues related to maintaining anonymity in web-based suicide awareness and prevention studies deserve further investigation.

A considerable number of participants responded to the debriefing questions and shared their thoughts and feelings related to depression and suicide and their feedback on The Truth about Suicide. Participants' responses indicated that conducting a web-based debriefing session was feasible and that the video had considerable impact on participants' thoughts and feelings regarding suicide. Conducting an effective debriefing session is very important in creating a safe and confidential setting for sharing thoughts, feelings, and experiences and in preventing iatrogenic effects of webbased suicide prevention programmes using emotionally charged videos.

In our study, Asian American college students rated the video significantly lower on cultural relevance than NHW students after controlling for covariates. A collectivist cultural orientation was significantly associated with cultural relevance, credibility and appeal. The findings confirmed that culturally relevant and tailored webbased suicide awareness programmes need to be developed for Asian Americans, a group at high risk for suicide. ${ }^{20}{ }^{37} \mathrm{~A}$ recent study showed that $<30 \%$ of college students who were severely depressed had received mental health treatment during the previous 12 months. ${ }^{38}$ Ethnic minority students (Asians, Pacific Islanders and Native Hawaiians) were even less likely than white students to seek help. Although diverse services have been provided by college counselling centres and the effectiveness of the programmes has been reported, the programmes are only effective to those that seek help. ${ }^{41}$ Suicide prevention programmes using the internet now receive more attention as an effective and efficient approach for today's college students. However, empirical data on the suitability of the programmes as well as the effectiveness of the approach for diverse groups are still very limited. Researchers ${ }^{42} 43$ 
claimed that one's cultural context is an essential component that needs to be taken into consideration in all kinds of suicidological research, even in this era of 'biologification' or focusing on genetic markers for suicidal behaviours.

The American Association of Suicidology guideline for suicide prevention programmes using videos also emphasises the importance of assessing whether the suicide prevention messages are clear and appropriate for the intended audience and if the video is sensitive to racial, ethnic, religious and gender differences. Videos made without considering the cultural values and behaviour of the target audience are ineffective in changing attitudes, particularly for stigmatised outcomes such as suicide. ${ }^{44}$ Findings from our study provide support for the relevance of the The Truth about Suicide video for NHW college students and (with some adaptation) for Asian American college students. It is unknown if there was any impact of the $\$ 20$ gift card on study feasibility, but the rapid accrual of the large sample from one university suggests that studies would be feasible without such an incentive for participation.

O'Connor and colleagues claimed that a nonconfrontational approach, including use of anonymous counselling services, is recommended for college students. ${ }^{14}$ The findings indicate that a culturally relevant web-based suicide awareness programme would be a very appropriate and effective strategy for promoting early detection of suicidal behaviours and promoting helpseeking behaviours among college students.

Disseminating a suicide awareness video using webbased technology is a feasible approach for suicide awareness and prevention for college students. The video content and web-based dissemination approaches need to be properly evaluated before being used for the target group.

Acknowledgements The authors are grateful to all the college students who participated in this study. Without their participation, the authors could have not conducted this study.

Contributors HC, HP, MLS, ZZ and DJW contributed to the planning of the study design, performed the study and mainly managed the study website. $\mathrm{HC}$ and HP conducted the literature review. HC, HP, MLS, ZZ and DJW contributed to the writing of the first draft of the manuscript. HP and $\mathrm{CP}$ mainly conducted statistical data analyses. HC, HP, MLS, CP, ZZ and DJW revised the manuscript. All authors approved the final version of the manuscript.

Funding The research reported in this manuscript was supported by the National Institutes of Health and the National Institute of Nursing Research (NINR), which supported the Center of Excellence for End-of-Life Transition Research (CEoLTR) at the University of Illinois at Chicago (grant number P30 NR010680). The web-based project was one of CEoLTR's supported research studies. In addition, this work was partially funded by the Seoul National University.

Disclaimer The contents of this paper are solely the responsibility of the authors and do not necessarily represent the official views of the NINR.

Competing interests None declared.

Patient consent Obtained.
Ethics approval The Institutional Review Board (IRB) of the University of Illinois at Chicago approved the study (IRB No. 2010-0457).

Provenance and peer review Not commissioned; externally peer reviewed.

Data sharing statement No additional data are available.

Open Access This is an Open Access article distributed in accordance with the Creative Commons Attribution Non Commercial (CC BY-NC 4.0) license, which permits others to distribute, remix, adapt, build upon this work noncommercially, and license their derivative works on different terms, provided the original work is properly cited and the use is non-commercial. See: http:// creativecommons.org/licenses/by-nc/4.0/

\section{REFERENCES}

1. CDC. National Center for Injury Prevention and Control, Web-based Injury Statistics Query and Reporting System (WISQARS). 2014 (cited 11 July 2016). http://www.cdc.gov/injury/wisqars/index.html (accessed 11 Jul 2016).

2. American College Health Association. American College Health Association-National College Health Assessment II: reference group executive summary. Hanover, MD: American College Health Association, Spring 2011.

3. Heron M. Deaths: leading causes for 2007. National vital statistics reports. Vol. 59. Hyattsville, MD: National Center for Health Statistics, 2011.

4. Xu JQ, Kochanek KD, Murphy SL, et al. Deaths: final data for 2007. National vital statistics reports. Vol. 58. Hyattsville, MD: National Center for Health Statistics, 2010.

5. Choi JL, Rogers JR, Werth JL. Suicide risk assessment with Asian American college students: a culturally informed perspective. Couns Psychol 2009;37:186-218.

6. Leong FT, Leach MM, Yeh C, et al. Suicide among Asian Americans: what do we know? What do we need to know? Death Stud 2007:31:417-34

7. Masuda A, L Anderson P, Twohig MP, et al. Help-seeking experiences and attitudes among African American, Asian American and European American College Students. Int $J$ Adv Counselling 2009;31:168-80.

8. Sue S. Asian American mental health: confronting difficult issues. Keynote address. Conference on Culture and Mental Health: Risk, Prevention, and Treatment for Asian Americans. Los Angeles, CA, 2011.

9. Suicide Prevention Resource Center. Kognito at-risk for university and college faculty: identifying and referring students in mental distress. 27 July 2009. http://www.sprc.org/bpr/section-III/kognitorisk-university-and-college-faculty-identifying-andreferring-students-menta (accessed 11 Feb 2011)

10. AFSP. The Truth About Suicide: Real Stories of Depression in College 2004 (cited 1 November 2012). http://www.afsp.org/ preventing-suicide/our-education-and-prevention-programs/ programs-for-teens-and-young-adults/the-truth-about-suicide-realstories-of-depression-in-college

11. Manning J, Vandeusen K. Suicide prevention in the dot com era: technological aspects of a university suicide prevention program. $J$ Am Coll Health 2011;59:431-3.

12. Ghoncheh R, Gould MS, Twisk JWR, et al. Efficacy of adolescent suicide prevention e-learning modules for gatekeepers: a randomized controlled trial. JMIR Mental Health 2016;3:e8.

13. Kauer SD, Mangan C, Sanci L. Do online mental health services improve help-seeking for young people? A systematic review. $J$ Med Internet Res 2014;16:e66. http://www.jmir.org/2014/3/e66/ (accessed 4 Mar).

14. O'Connor PJ, Martin B, Weeks CS, et al. Factors that influence young people's mental health help-seeking behaviour: a study based on the Health Belief Model. J Adv Nurs 2014;70:2577-87.

15. Chu JP, Hsieh K-Y, Tokars DA. Help-seeking tendencies in Asian Americans with suicidal ideation and attempts. Asian Am J Psychol 2011;2:25.

16. Bryan CJ, Dhillon-Davis LE, Dhillon-Davis KK. Emotional impact of a video-based suicide prevention program on suicidal viewers and suicide survivors. Suicide Life Threat Behav 2009;39:623-32.

17. Tsai JL, Chentsova-Dutton $Y$. Different models of cultural orientation in American-and overseas-born Asian Americans. In: Kurasaki KS, Okazaki S, Sue S, eds. Asian American mental health: assessment theories and methods. New York: Kluwer Academic/Plenum Publishers, 2002:xv, 344

18. Trafimow D, Triandis HC, Goto SG. Some tests of the distinction between the private self and the collective self. J Pers Soc Psychol 
1991;60:649-55.

19. Singelis TM, Triandis HC, Bhawuk DPS, et al. Horizontal and vertical dimensions of individualism and collectivism: a theoretical and measurement refinement. Cross Cultur Res 1995;29:240-75.

20. Triandis HC. Individualism and collectivism. Boulder, CO: Westview, 1995.

21. Eskin M. The effects of individualistic-collectivistic value orientations on non-fatal suicidal behavior and attitudes in Turkish adolescents and young adults. Scand J Psychol 2013;54:493-501.

22. King CA, Eisenberg $D$, Zheng $\mathrm{K}$, et al. Online suicide risk screening and intervention with college students: a Pilot Randomized Controlled Trial. J Consult Clin Psychol 2015;83:630-6.

23. Bowen DJ, Kreuter M, Spring B, et al. How we design feasibility studies. Am J Prev Med 2009;36:452-7.

24. Haas A, Koestner B, Rosenberg J, et al. An interactive web-based method of outreach to college students at risk for suicide. J Am Coll Health 2008;57:15-22.

25. Lai MH, Maniam T, Chan LF, et al. Caught in the web: a review of web-based suicide prevention. J Med Internet Res 2014;16:e30.

26. Robinson J, Hetrick S, Cox G, et al. The safety and acceptability of delivering an online intervention to secondary students at risk of suicide: findings from a pilot study. Early Intervent Psychiatry 2015;9:498-506.

27. Murphy SL, Xu JQ, Kochanek KD. Deaths: final data for 2010. National vital statistics reports. Vol. 61. Hyattsville, MD: National Center for Health Statistics, 2013.

28. Suicide Prevention Resource Center. Suicide among racial/ethnic populations in the US. Whites, 2014.

29. Park $\mathrm{H}$, Choi $\mathrm{H}$, Suarez ML, et al. Predictors of valid engagement with a video streaming web study among Asian American and non-Hispanic White college students. Comput Inform Nurs 2014;32:156-65.

30. Ong $A D$, Weiss $D J$. The impact of anonymity on responses to sensitive questions1. J Appl Soc Psychol 2000;30:1691-708.

31. Warner $\mathrm{CH}$, Appenzeller GN, Grieger T, et al. Importance of anonymity to encourage honest reporting in mental health screening after combat deployment. Arch Gen Psychiatry 2011;68:1065-71.
32. Domino G, Gibson, L., Poling, S., et al. Students' attitudes towards suicide. Soc Psychiatry 1980;15:127-30.

33. Domino G, Moore D, Westlake L, et al. Attitudes toward suicide: a factor analytic approach. J Clin Psychol 1982;38:257-62.

34. Limbacher M, Domino G. Attitudes toward suicide among attempters, contemplators, and nonattempters. Omega J Death Dying 1985;16:325-34

35. Oyserman D, Coon HM, Kemmelmeier M. Rethinking individualism and collectivism: evaluation of theoretical assumptions and meta-analyses. Psychol Bull 2002;128:3-72.

36. Herek GM, Gillis JR, Glunt EK, et al. Culturally sensitive AIDS educational videos for African American audiences: effects of source, message, receiver, and context. Am J Community Psychol 1998;26:705-43.

37. U.S. Public Health Service. The surgeon general's call to action to prevent suicide. Washington DC, 1999

38. Herman S, Archambeau OG, Deliramich AN, et al. Depressive symptoms and mental health treatment in an ethnoracially diverse college student sample. J Am Coll Health 2011;59:715-20.

39. Drum DJ, Brownson C, Burton Denmark A, et al. New data on the nature of suicidal crises in college students: Shifting the paradigm. Prof Psychol 2009:40:213-22.

40. Moutier C, Norcross W, Jong P, et al. The suicide prevention and depression awareness program at the University of California, San Diego School of Medicine. Acad Med 2012;87:320-6.

41. Pasco S, Wallack C, Sartin RM, et al. The impact of experiential exercises on communication and relational skills in a suicide prevention gatekeeper-training program for college resident advisors. $J$ Am Coll Health 2012;60:134-40.

42. Hjelmeland $\mathrm{H}$. Cultural context is crucial in suicide research and prevention. Crisis J Crisis Intervent Suicide Prev 2011;32:61-4.

43. Jo KH, An GJ, Sohn KC. Qualitative content analysis of suicidal ideation in Korean college students. Collegian 2011;18:87-92.

44. Polansky JM, Buki LP, Horan JJ, et al. The effectiveness of substance abuse prevention videotapes with Mexican American adolescents. Hispanic J Behav Sci 1999;21:186-98. 